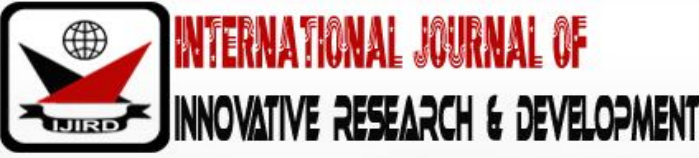

ISSN 2278 - 0211 (Online)

\section{Logistic Regression Analysis of Drivers' Behaviour in Calabar Metropolis, Cross River State, Nigeria}

\author{
Dr. Inah Eteng Okon \\ Senior Lecturer, Department of Geography \& Environmental Science, \\ University of Calabar, Calabar, Nigeria
}

\begin{abstract}
:
The paper applied the driver behaviour questionnaire with closed-ended questions on drivers in locations purposively sampled to reflect different landuse categories. Socio-economic characteristics of drivers and travel behaviour were contained in the DBQ. Logistic regression analysis was conducted to predict the behaviour of drivers for 347 household heads (90.4\% success rate) using reasons for violation traffic, gender, age, education ownership of valid driver license and driver category as predictors. A test of the full model against a constant only model was statistically significant, indicating that the predictors as a set reliably distinguished between traffic violators and non-traffic violators (chi square $=89.113, \mathrm{p}<.001$ with $\mathrm{df}=8)$. Prediction success overall was $94.2 \%$ (91.3\% for non-violation and $96.2 \%$ for traffic violation. The Wald criterion demonstrated that impatience, emergency, weak law, and other factors made a significant contribution to prediction in model $1(\mathrm{p}=.000)$, while only ignorance did not $(\mathrm{p}=.999)$. The study in line with reviewed literature has shown that when traditional cities increase in population and level of commercial activities, there is bound to be mobility conflicts if not properly managed. Enforcement of traffic laws, strategies directed at improving the safety management system, road safety awareness campaigns, among others were recommended.
\end{abstract}

Keywords: Driver behaviour questionnaire, traffic violation, intersection, traffic count

\section{Background}

Transportation is the hub of any economy as it connects people and activity centres thus providing accessibility to places. Roles of urban transportation systems are often likened to that of the blood circulatory system without which the body cannot be nourished and made to function properly. Urban centres are locations having a high level of accumulation and concentration of economic activities and a complex spatial structure that are supported by transport systems (Rodriguez, 2009). The functioning of urban economic activities depends to a large extent on the adequacy and efficacy of its transport system. When transport system for a variety of reasons cannot satisfy the numerous requirement of urban mobility, transport problems ensue, the most significant being changing drivers' behaviour.

Urban centres are locations of intense economic and social activities. This is made possible by transport systems which are the veins and arteries of urban areas linking social and functional zones. The transportation needs of a country and general mobility problems become apparent as the community becomes larger and complex (Sule, 2008). There has been increase in number of vehicles plying the roads of Calabar, especially after the ban on motorcycles in the metropolis in November, 2009. Consequently, car ownership rates have been on the increase at unprecedented levels. Overtime, the state of automobile dependence has ensued as there is no other alternative to urban mobility making the automobile the sole means of mobility.

Due to incessant increase in population, increase in household incomes and its resultant increase in car ownership coupled with poor land-use planning, poor transport design and planning, traffic congestion has become an intractable problem in Nigeria cities (Aderamo, 2012). Although the rising automobile mobility in Calabar can be perceived as a positive consequence of rising incomes and standard of living, this acute growth in the congestion at peak traffic hours on major roads like Etta Agbor, Marian, MCC and Calabar Road, and so on. Indiscipline and ignorance on the part of motorists who are illtrained remains part of the problem of traffic congestion. Inadequate off-street parking facilities in especially in the business districts often make motorists to park on the road, narrowing the road corridors, further exacerbating congestion.

Driving provokes anger more often than other activities. Driving is goal oriented activity, the purpose being to get from point A to point B expeditiously; yet people easily and frequently thwart driving goals. It is also a very stressful activity 
that exposes drivers and passengers to potential significant dangers. Anger may, but usually does not lead to aggressive driving or road rage. Situational, cultural, and individual factors combine to cause angry drivers to behave aggressively behind the wheel.

With growing demands on the road as a major mode of transport, different metropolitan transport organisations cannot function efficiently due to stress and neglect of traffic education and training programmes for the operators/drivers. This is particularly the case in many developing countries like Nigeria. The behaviour of motorists (and pedestrians) on transportation networks always play major role in the flow of traffic. Transportation planning researches (for e.g. Fuller, 2005; Alm \& Nilsson, 1995; Lajunen \& Summala, 2003; Aberg, \& Rimmo, 1998) have shown that driver behaviour on a transport network can either cripple or enable the effective flow of vehicles in the network. The behaviour of drivers in any network depends on various factors associated with an individual driver and the enforcement of transport policies. The factors associated with these behaviours range from gap acceptance, drivers' perception, and driver reaction, car following behaviour, travel choices, aggressive driving, drunken driving, inadequate road signage, intersection design and others. The relationship between the driver's behaviour and the acceptable and or available gap remains an essential part of predicting the effective flow of vehicles on a network. This is given that most accidents that are caused on collector, urban and rural roadways are due to transportation road network.

The study investigated the behaviour of drivers in Calabar especially at major intersections. Calabar is the capital city of Cross River State, southern Nigeria. The city is watered by the Calabar and Great Kwa Rivers and Creeks of the Cross River (from its inland delta). It has an area of $406 \mathrm{~km}^{2}$ and a population of 371,022 at the 2006 census (estimated at over 400,000 as at 2017). Calabar is located at the extreme of South Eastern Nigeria between latitude 4045 $\mathrm{N}$ and 50301S and longitude 8015트 and $8^{021} \mathrm{IW}$. The city lies on a peninsular formed by the Calabar River, the Kwa River, the Cross-River Estuary and the Atlantic Ocean (Figure 1)

\subsection{The Problem}

Human behaviour on transportation networks always play major role in the flow of traffic. Transportation planning research shows that driver behaviour on a transport network can either cripple or enable the effective flow of vehicles in the network. The drivers' behaviour depends on various factors associated with an individual driver and the network. The factors associated with the drivers' behaviour ranges from gap acceptance, drivers' perception, and driver reaction, car following behaviour, travel choices, aggressive driving and others.

An essential part of predicting the effective flow of vehicles on a network is the relationship between the driver's behaviour and the acceptable and or available gap. Most accidents that are caused on collector, urban and rural roadways are due to transportation road network. However, less effort has been spent on the relationship between driver behaviour and acceptance at priority intersections, defined as intersections that are controlled by a stop or yield sign, or a flashing beacon. A driver approaching an intersection on a minor road onto the major road must take a decision on when to join, cross or merge into the roadway. The available gap between two vehicles on the main road is an important factor for the driver and must determine if the gap is sufficient to accept. 


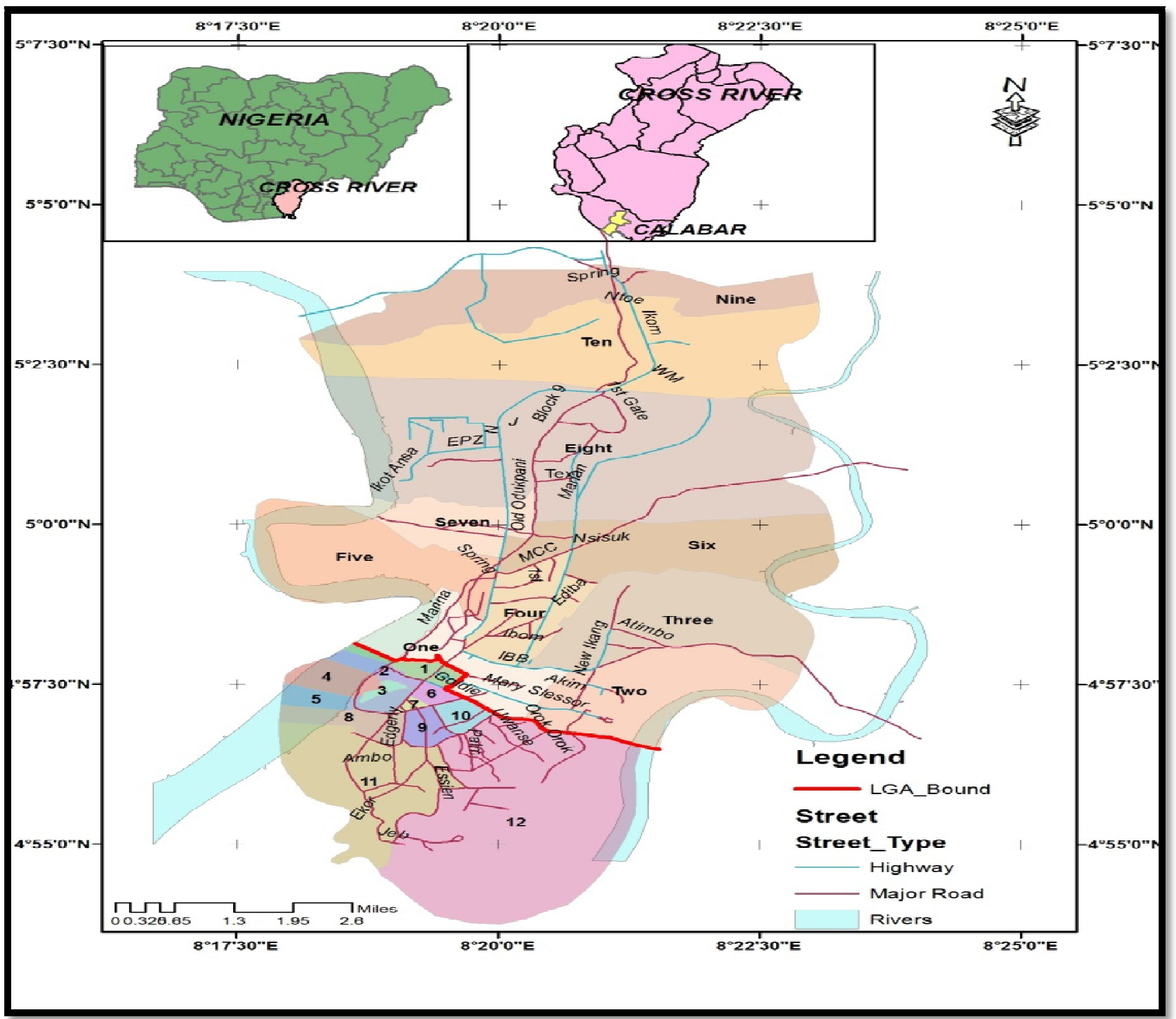

Figure 1: Calabar Metropolis Showing Wards and Major Road Network Insert

Nigeria Showing Cross River State; Cross River State Showing Calabar Metropolis

Various factors that affect the driver's decision to accept or reject a gap are as follows: driver's socio-economic characteristics such as level of education, income, gender, age, experience in driving, level of familiarity with an area, the ability to estimate a vehicle's speed for oncoming traffic, condition of traffic, the type of vehicles, types of gaps, such as lead gap, lag gap, and front gap, environmental conditions, driver-inter-influence, size of queue behind the driver, the number of vehicles entering the gap, and its distance. The most difficult gap to accept at un-signalized intersections is when left turning vehicles from minor road are turning onto major roads.

Urban centres are locations of intense economic and social activities. This is made possible by transport systems which are the veins and arteries of urban areas linking social and functional zones. The transportation needs of a country and general mobility problems become apparent as the community becomes larger and complex. There has been increase in number of vehicles plying the roads of Calabar, especially after the ban on motorcycles in the metropolis in November, 2009. Consequently, car ownership rates have been on the increase at unprecedented levels. Overtime, the state of automobile dependence has ensued as there is no other alternative to urban mobility making the automobile the sole means of mobility.

Due to increasing population, increase in household incomes and its resultant increase in car ownership coupled with poor land-use planning, poor transport design and planning, traffic congestion has become an intractable problem in the city. Although the rising automobile mobility in Calabar can be perceived as a positive consequence of rising incomes and standard of living, this acute growth in the congestion at peak traffic hours on major roads thoroughfares like Etta Agbor, Marian and Calabar Road (CBD). Indiscipline and ignorance on the part of motorists who are ill-trained adds to the problem of traffic congestion. Inadequate on-street parking facilities, narrow road network and so compound an already worse traffic problem in the city 


\section{Literature Review}

Driver behaviour is often studied by using self-reports and questionnaires. Despite their obvious advantages, questionnaires are vulnerable to socially desirable response tendencies. Lajunen and Summala (2003) studied the effects of socially desirable responding on self-reports of driving by recording self-reports of driving in both public and private settings. In public settings, 47 applicants for a driving instructor training course completed the driver behaviour questionnaire (DBQ) and balanced inventory for socially desirable responding as a part of the entrance examination. In a private setting, 54 students of that training course completed the same questionnaires anonymously in the classroom. ANOVA results showed a difference between the two settings in six DBQ item scores, such that aberrant behaviours were reported less frequently in public than in private settings. The results indicated that bias caused by socially desirable responding is relatively small in DBQ responses.

Forty-eight drivers answered a set of written questions about their driving style and drove a pre-defined, mixed urban and motorway route under observation in the study of West, French, Kemp and Elander (1993). For 20 drivers there was a second observer in the car to check on inter-observer reliability. Relationships were examined between self-reports of driver behaviour and observers' reports, and between both of these and the number of accidents in which the drivers had been involved in the past three years. The results indicated that there was good inter-observer agreement on a number of important variables including speed, calmness, and attentiveness.

In their paper, (Aberg \& Rimmo, 1998), a study of driver errors was replicated in a survey of over 1400 drivers. New error items were added to the Driver Behaviour Questionnaire (DBQ). An analysis of data based on the original DBQ confirmed the three-factor structure obtained. When new items were included in the analysis a four-factor solution was found to be more appropriate. Two of the four factors correspond to the two factors presented previously, namely violations and dangerous errors, while the third factor, harmless lapses, was split into two new factors, inattention errors and inexperience errors in the present study. Inattention errors were shown to be of special interest as the scores for this factor increased with age, thus indicating errors that might be caused by automatization of driver behaviour.

Lajunen, Parker and Summala (2004) investigated if the original factorial structure of the Manchester Driver Behaviour Questionnaire (DBQ) was replicated in Finland and The Netherlands. A postal questionnaire survey of drivers was carried out in Britain, Finland and The Netherlands. Exploratory factor analysis together with target (Procrustes) rotation and factorial agreement indexes were calculated to investigate the applicability of Finnish and Dutch versions of DBQ. Results of the factor comparisons showed that the DBQ four-factor structures found in Finland and The Netherlands were congruent but not perfect with the target structure found in Britain. Reliabilities of the scales were around the same level as in the British data.

Dia (2002) presents an agent-based approach to modelling individual driver behaviour under the influence of realtime traffic information. The driver behaviour models developed in his study were based on a behavioural survey of drivers which was conducted on a congested commuting corridor in Brisbane, Australia. Commuter's responses to travel information were analysed and a number of discrete choice models were developed to determine the factors influencing driver's behaviour and their propensity to change route and adjust travel patterns. Based on the results obtained from the behavioural survey, the agent behaviour parameters which define driver characteristics, knowledge and preferences were identified and their values determined

Summala (1996) observed that risk-related behaviour should be considered at several hierarchical levels with different mechanisms to produce 'risk compensation'. At a high level, trip decisions modify populations at risk in different circumstances, sometimes attenuating, sometimes amplifying population risk differences. At a low level of vehicle control and guidance in real dynamic traffic situations, simpler control mechanisms which result in behavioural adaptation can be identified. All these effects influence the end result of accident risk as separate mechanisms.

However, Schmidt (1992) and Gardner and Altman (1986) explained that individual studies contain only little information and that apparent inconsistencies in the effect sizes and p-values can usually be explained through sampling error alone. A meta-analysis is essential to cope with sampling error, to expose the consistency of the effects, and to aid in theory forming (Schmidt, 1992). His study used a meta-analysis to estimate the predictive correlations of the DBQ errors and violations factors with regard to self-reported and registered accidents. The effects of age, gender, and exposure (mileage and hours driven per week) were evaluated as well, as these variables are known confounders of accident involvement (Lourens, Vissers, \& Jessurun, 1999; Massie, Campbell, \& Williams, 1995). This study employed binary regression analysis to predict driver behaviour under different road traffic circumstances.

\section{Method of Study}

This paper used the descriptive research design approach wherein observation, measurement and description of the behavior of drivers were investigated. Primary sources of data including a validated structured driver behaviour questionnaire administered to mainly drivers. Direct observations and traffic counts were employed. Other sources of data included journal articles and government publications which formed part of study background. The National Population Commission (NPC, 1990) showed that Calabar metropolis had a population of 328,878 in 1991 (136, 440 persons for Calabar Municipal and 192,438 persons for Calabar South Local Government Area). The total population of the metropolis in the 2006 census was given as 371, 220; however, our projection was carried out based on the 1991 census since the 2006 population figures for localities is yet to be published using the growth rate of 2.54 percent in 1991 (World Bank, 2015). The continued 
development of the city has led to an increased projected population of 402,843 for 2017. Given the population of the area in 1991 , the City had a population density of 2,399 while in 2006 , the density was 2,737 persons per sqkm.

In order to select the route for study in the metropolis, the purposive sampling technique was employed. This technique allows the researcher the freedom to draw samples from parent population from her discretion based on some predefined attributes such as high volume of drivers, willingness of literate respondents to participate in the survey and proximity to commercial, high income residential and institutional land uses. This enhanced the quality of responses from different categories of drivers (Table 1). This is done to achieve a fair representation of all communities and driver categories. The study acknowledges the fact that the sample size may not be practically large enough for some sort of conclusion, however, there constitute averages that can give direction of what accounts for driver behavior in the city.

A reconnaissance survey was carried out along major roads in the Calabar metropolis. From this survey, routes with high rate of congestion and traffic violations were identified. Data was collected through traffic count and simple hand tally method on selected routes. This was done with the aid of field research assistants with orientation on traffic count. This was done at different peak periods, during rush hours of the day from 7am-9am in the morning and 2pm-4pm in weekdays and weekend at major intersections. 384 validated structured questionnaires were administered randomly to drivers.

The questionnaires contained socio-economic characteristics of road users, issues relating to traffic congestion such as existence of traffic violations, days of violation, most violating time, and reasons for traffic violation, the purpose of trips expressed as a percentage of all trips taken on weekdays and weekends respectively, most violated time of the day and measures to curb traffic violations. However, due to difficulties such as the attitude of road users to answering the questionnaire, a total of 347 questionnaires were returned.

Both descriptive and inferential statistical techniques were used to analyze data. Descriptive analysis includes modal split of vehicles, the use of simple averages, percentage, tables and charts to summarize the data. In order to analyze the data obtained from census of violating modes at the studied intersections, they were converted to passenger car units (Table 2). Logistic regression analysis was conducted on the dataset to predict categorical variable (driving behaviour of 347 drivers, $90.4 \%$ success rate) from many predictor variables

\begin{tabular}{|c|c|c|}
\hline Variable & Administered tools & Retrieved tools \\
\hline Federal Secretariat & 40 & 35 \\
State Secretariat & 40 & 32 \\
Unical & 40 & 34 \\
Crutech & 40 & 35 \\
Etim Edem Park & 40 & 40 \\
Calabar Municipality Headquarter & 40 & 32 \\
Calabar South Head & 40 & 37 \\
Psychiatric Hospital & 35 & 40 \\
Mobil Filling Station & 35 & 30 \\
UCTH & 34 & 32 \\
Total & 384 & 347 \\
\hline
\end{tabular}

Table 1: Driver Behaviour Survey in Localities of Calabar

\begin{tabular}{|c|c|}
\hline Mode & PCUs \\
\hline Cars & 1.0 \\
Buses & 1.5 \\
Pick-up/ Vans & 2.0 \\
Lorry/truck & 2.5 \\
Trailer/ tanker & 3.0 \\
\hline
\end{tabular}

Table 2: Passenger Car Unit Equivalent (Pcus)

Source: Crowther, Et Al (1964)

Such as Reasons for Violation, Sex, Age, Education,

Ownership of License, and Driving Class

\section{Results and Discussion of Findings}

\subsection{Socioeconomic Characteristics of Respondents}

The Sex distribution of the respondents from Table 3 shows that males accounted for $60.6 \%$ while $39.4 \%$ were females. This implies that more male's drivers participated in the survey. Also, the males were more responsive in answering the questionnaire than the females. The age pattern revealed that $40.6 \%$ of drivers were between the ages of $36-45$ years, $33.3 \%$ were between 26 - 35 years, $13.3 \%$ were between 45 - 55 years, $7.8 \%$ were between 18-25years, $4.6 \%$ comprised of drivers that are 56 and above, while 3\% were below 18 years. This indicates that the traffic environment of Calabar Metropolis comprises of an active population of respondents belonging to working class group of the workforce who toil for various reasons ranging 
from schooling, leisure, work and business and so on. The marital status shows that $63.6 \%$ of the respondents are married, $5.4 \%$ and $2.9 \%$ were divorced and widowed respectively. The single notwithstanding their status were $28.0 \%$. This indicates that married men and women have better access to car according to this survey.

\begin{tabular}{|c|c|c|}
\hline Variable & Frequency & Percentage \\
\hline Sex & & \\
Male & 200 & 60.6 \\
Female & 130 & 39.4 \\
Marital status & & \\
Single & 67 & 28.0 \\
Married & 152 & 63.6 \\
Divorced & 13 & 5.4 \\
Widowed & 7 & 2.9 \\
Age & 1 & .3 \\
<18 & 27 & 7.8 \\
18-25 & 115 & 33.3 \\
26-35 & 140 & 40.6 \\
36-45 & 46 & 13.3 \\
45-55 & 16 & 4.6 \\
56> & & \\
Educational qualification & 16 & 4.6 \\
No formal education & 14 & 4.1 \\
FSLC & 33 & 9.6 \\
SSCE/ WAEC & 54 & 15.7 \\
NCE/ DIP & 140 & 40.6 \\
HND/ BSc & 76 & 22.0 \\
Post Grad & 12 & 3.5 \\
Other & & 35.8 \\
Occupation & 124 & 25.4 \\
Civil service & 88 & 17.6 \\
Public service & 61 & 10.4 \\
Business & 36 & 6.8 \\
Driver & 13 & \\
Artisan & 24 & \\
Other & & \\
\hline
\end{tabular}

Table 3: Socioeconomic Variables of Respondents

The educational qualification of respondents reveals that $40.6 \%$ has HND/ BSc, $22.0 \%$ has Post Graduate Diploma, $15.7 \%$ has NCE/ DIP, 9.6\% has SSCE/ WAEC, $4.6 \%$ has no formal education, $4.1 \%$ has FSLC and 3.5\% had other qualifications. This implies that over $90 \%$ of the road users are literate and perhaps are conscious of the traffic rules in the area. The reason for a high proportion of $\mathrm{HND}$ / BSc holders may be due to sample locations. The Post Graduates also added to the traffic volume because most of them are also working and can afford to own a car. The occupational structure showed that $35.8 \%$ of the respondents were Civil Servants, 25.4\% were Public Servants, $17.6 \%$ were Business men and women, $10.4 \%$ were professional drivers, while 3.8\% were Artisans from the informal sector. This implies that Civil Servants constitute greater percentage of commuters mainly because the economy of Cross River State is government Sector driven. The Public Servants also have high proportion of workforce in the country. The percentage of business men and women indicated that the private sector is gradually improving. It also reveals that most of the commuters plying the road are professional drivers having undergone several trainings and obtained valid licenses from Government recognized institutions. Above all, the occupational structure clearly shows that respondents engage in ventures that require mobility, either generating or attracting trips.

A cross tabulation of educational qualification of respondents and their car ownership status reveal that about 4.7 per cent of the total respondents having a car do not acquire formal education. Similarly, 3.5\%, 7.9\%, and 11.4\% of respondents owning car have FSLC, SSCE/ WAEC, and NCE/ DIP respectively. Furthermore, of the 85.2\% HND/ Bachelor respondents, 35.6\% responded yes to car ownership while only $5.0 \%$ do not own a car. Respondents with post graduate degrees accounts for $18.7 \%$ car owners and 3.2\% non-car owners in the survey. Further cross tabulation of educational qualification and number of cars own shows that $82.7 \%$ of the respondents responded to 1 car ownership, 33.6\% of which belong to HND/ Bachelor; $12.2 \%$ own 2 cars, $2.0 \%$ own 3 cars while $3.1 \%$ reported having 4 cars.

From Table 4, it is seen that chi-square (2) 13.056, p < 0.05, which reveals that there is statistically significant association between education and car ownership status. The probability of the chi-square test statistic (chi-square $=13.056$ ) was $p=0.000$, less than the alpha level of significance of 0.05 . The research hypothesis that 'educational qualification and car ownership are independent' is therefore rejected, and thus concludes that there is a relationship between the two variables. 
Phi and Cramer's V in Table 5 are both tests of the strength of association. We can conclude that the strength of association between the variables is low (.195). The understanding that HND/ Bachelor constitute minimum middle-income requirement for job placement is a probable reason to accept this result. Whereas the result is true for the study population, it may not be so true for the entire city.

\begin{tabular}{|c|c|c|c|}
\hline Variable & Value & df & Asymp. Sig. (2-sided) \\
\hline Pearson Chi-Square & $13.056 \mathrm{a}$ & 6 & .042 \\
Likelihood Ratio & 16.019 & 6 & .014 \\
Linear-by-Linear Association & .119 & 1 & .730 \\
Nof Valid Cases & 343 & & \\
\hline
\end{tabular}

Table 4: Chi-Square Tests

a. 4 Cells (28.6\%) Have Expected Count Less Than 5 the Minimum Expected Count Is 1.78

\begin{tabular}{|c|c|c|}
\hline Variable & Value & Approx. Sig. \\
\hline Nominal by Nominal Phi & .195 & .042 \\
Cramer's V & .195 & .042 \\
N of Valid Cases & 343 & \\
\hline
\end{tabular}

Table 5: Symmetric Measures

\subsection{Car Ownership Characteristics of Respondents}

Table 6 shows that $85.2 \%$ of respondent owned one or more cars while $14.8 \%$ did not own any but ply the road with government, commercial, families or friends' cars. The table reveals that $82.4 \%$ of drivers actually own one (1) car, $12.5 \%$ owns 2 cars, $2.0 \%$ owns 3 cars while 3.0\% could afford 4 cars. This implies that the economy of the country affects the purchasing power of the populace; hence, a high percentage of drivers can only afford a car. Those who own more than one car may have own chains of businesses across the state and their businesses may require mobility. A cross tabulation of this data revealed a positive correlation between marital status and number of cars own. The driving status reveals that $97.4 \%$ of the respondents can drive while $2.6 \%$ cannot drive. In the course of this work, it was observed that part of the percentage of those who cannot drive actually own a car but have phobia for driving and prefers to employ drivers.

The Table (6) also shows that $74.6 \%$ of the respondents possess valid drivers' licenses while $25.4 \%$ ply the road without drivers' license. $79.9 \%$ confirmed ownership of a valid drivers' license by displaying the licenses to the researcher. $20.1 \%$ of the respondents could not confirm their drivers' license status owing to the fact that they do not have any. $47.8 \%$ had expired licenses, $31.5 \%$ had no money to process a valid drivers' license, $14.1 \%$ complained of long processes to acquire one.

\begin{tabular}{|c|c|c|}
\hline Variable & Frequency & Percentage \\
\hline Car ownership & 293 & 85.2 \\
Yes & 51 & 14.8 \\
No & & \\
Yes to car ownership & 244 & 82.4 \\
1car & 37 & 12.5 \\
2cars & 6 & 2.0 \\
3cars & 9 & 3.0 \\
4>cars & 334 & 97.4 \\
Driving status & 9 & 2.6 \\
Yes & & \\
No & 255 & $74.6 \%$ \\
Yes & 87 & $25.4 \%$ \\
No & & \\
Drive license ownership & 639 & $79.9 \%$ \\
Confirmed & 60 & $20.1 \%$ \\
Not confirmed & & \\
Driver license ownersip confirmation & 29 & 31.5 \\
Re money & 44 & 47.8 \\
Expired & 13 & 14.1 \\
Other & 6 & 6.5 \\
\hline
\end{tabular}

Table 6: Car Ownership and Driving Status of Respondents 


\subsection{Travel Characteristics of Respondents}

Most of the respondents (about $63.4 \%$ ) in the study area undertake 1-3 trips daily. about $29.8 \%$ of them accounts for 4-6 trips while only 6.8\% responded to doing 7-9 daily trips (Table 7). Results in figure 2 shows that on weekdays, work had $70.3 \%$ and $29.7 \%$ on weekends, worship/ religion had $10.4 \%$ on weekdays and $25.3 \%$ on weekends, school had $10.1 \%$ on weekdays and $9.2 \%$ on weekends, shopping had $4.7 \%$ on weekdays and $19.7 \%$ on weekends, recreation had $3.7 \%$ on weekdays and $15.1 \%$ on weekends while other activities had $0.7 \%$ on weekdays and $1.0 \%$ on weekends respectively. The implication of this is that, Calabar being a civil service state, have high proportion of the workforce ply the road on weekdays for official assignments while the figure declined on weekends owing to the fact that Civil Servants rests on weekends except those on special duties. Worship/ religious activities declined in weekdays but increased on weekends because respondents had time to attend. Most students are not mobile, hence, the low percentage on school activities on both weekdays and weekends. Few respondents had time on weekdays to go on shopping spree and more time on weekends. The table shows that most respondents rarely have time for recreational activities both on weekdays and weekends, hence the low proportion recorded. All these activities require mobility.

\begin{tabular}{|c|c|c|}
\hline Variable & Frequency & Percentage \\
\hline Average number of trips per day & & \\
$1-3$ & 187 & 63.4 \\
$4-6$ & 88 & 29.8 \\
$7-9$ & 20 & 6.8 \\
\hline
\end{tabular}

Table 7: Travel Characteristics of Respondents

*A Trip Defined As Origin to Destination Not Necessarily Home-Based Destination, But Any Movement Satisfying a Purpose

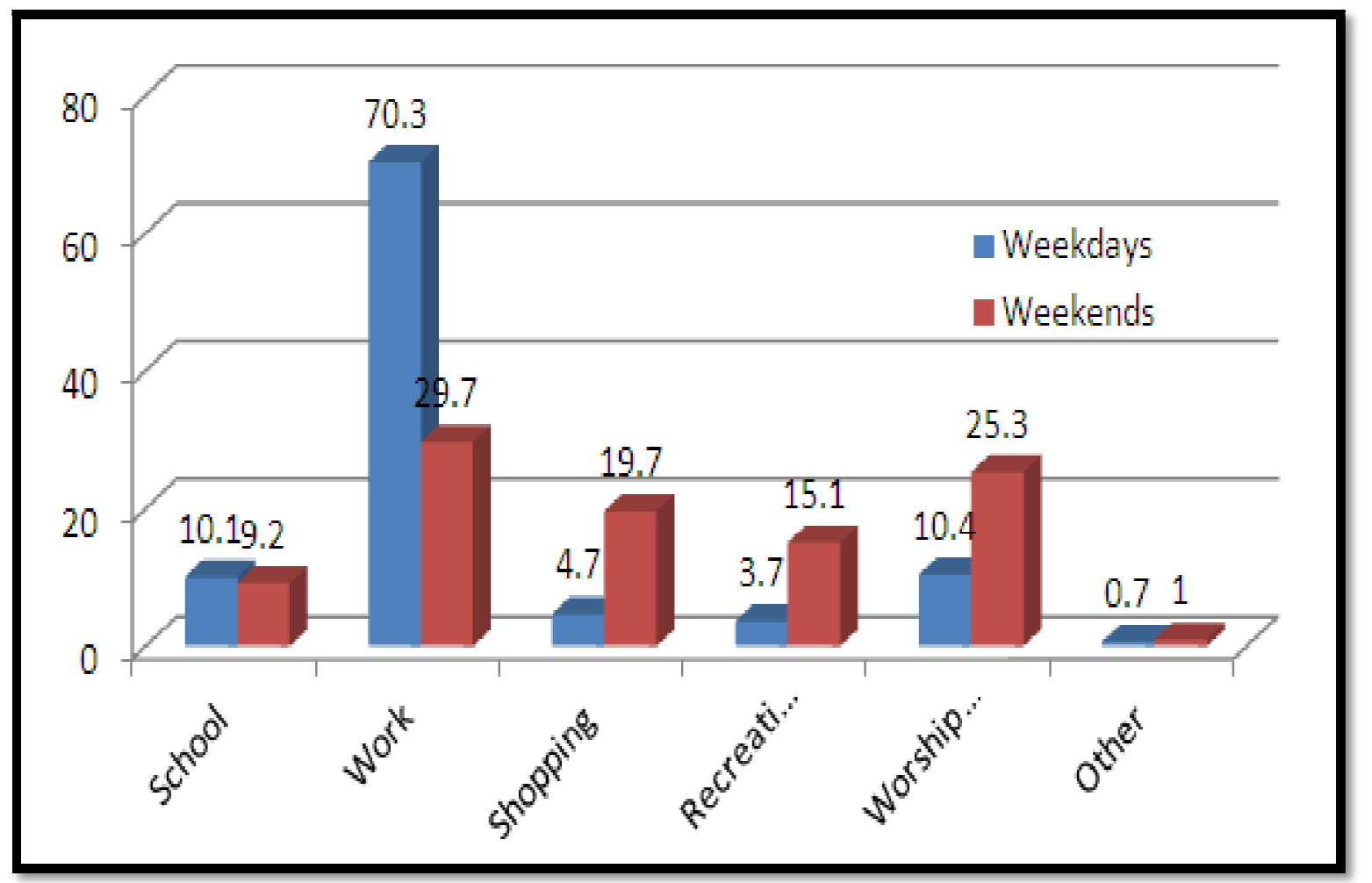

Figure 2: Comparison between Trips during Weekdays and Weekend

\subsection{Traffic Violations in the Study Area}

Table 8 reveals that $59.2 \%$ of the respondents actually accepted violating the traffic while $40.8 \%$ denied ever violating. Emergency situation accounts for most violations by respondents trying to arrive at destinations on time to attend to urgent needs or save a situation e.g. the fire fighter trucks, ambulances, Government convoy etc. About $65.2 \%$ of the respondents gave their reasons for not violating the traffic as being law abiding citizens and also aware of the punitive measures on violators.

About $44.9 \%$ of respondents also assumed that others violate because of indiscipline nature of the drivers. They drink before or while driving and also beat the traffic unnecessarily. $76.3 \%$ accounted for emergency as conditions for tolerable violations to save life or arrest a situation. All these imply that traffic violation is the major drivers' behaviour in intersections. Figure 3 for example reveals the volume of violations by modal split at major intersections in Calabar. In all sampled intersections, the car is recorded as violating more traffic than any other mode. This perhaps is illustrative of the dominance of 
car traffic in the city for personal and public use. Most violations were recorded in University of Calabar roundabout. This is mostly expected as the university remain a significant traffic generator from both students and staff alike.

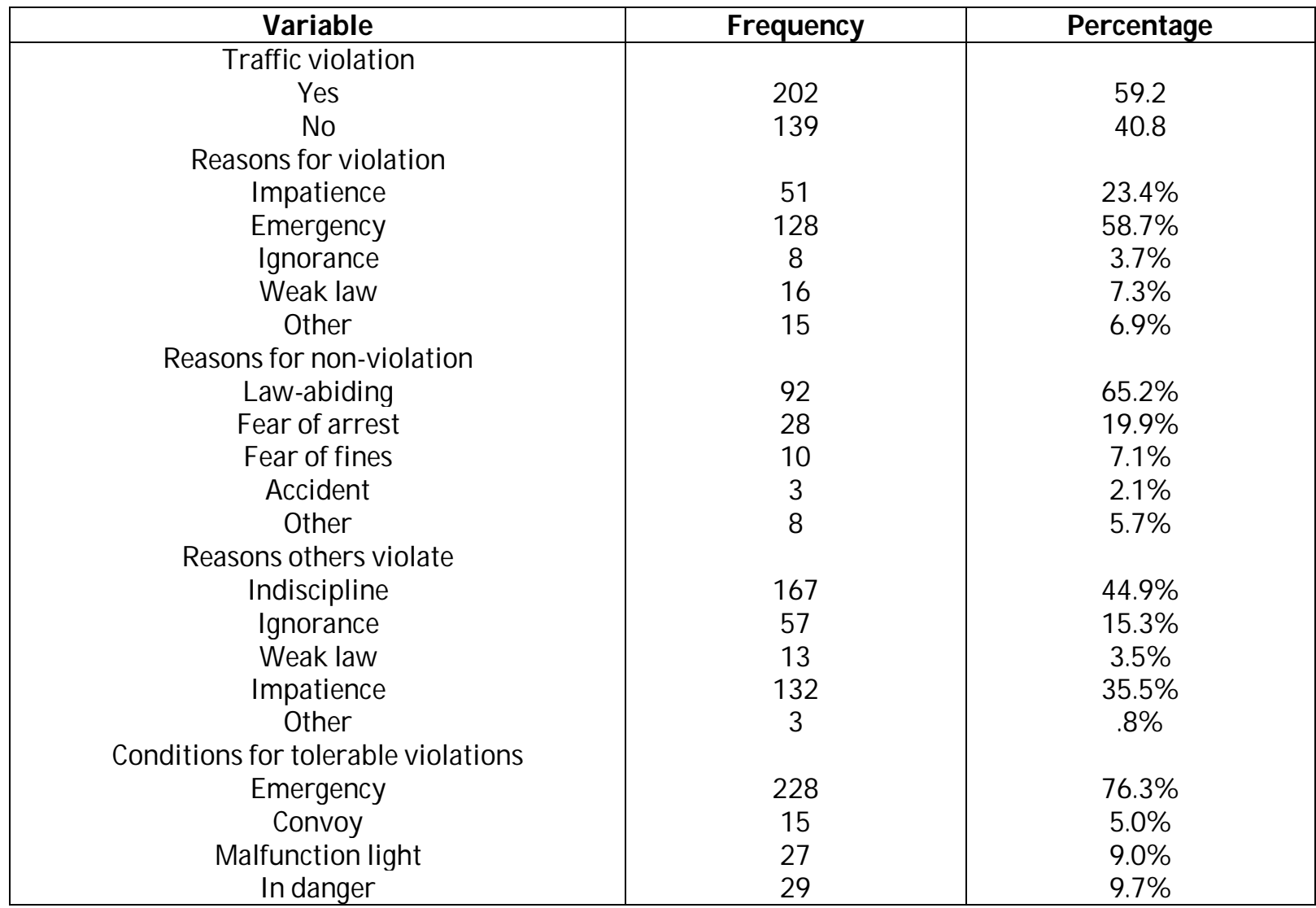

Table 8: Traffic Violation by Respondents

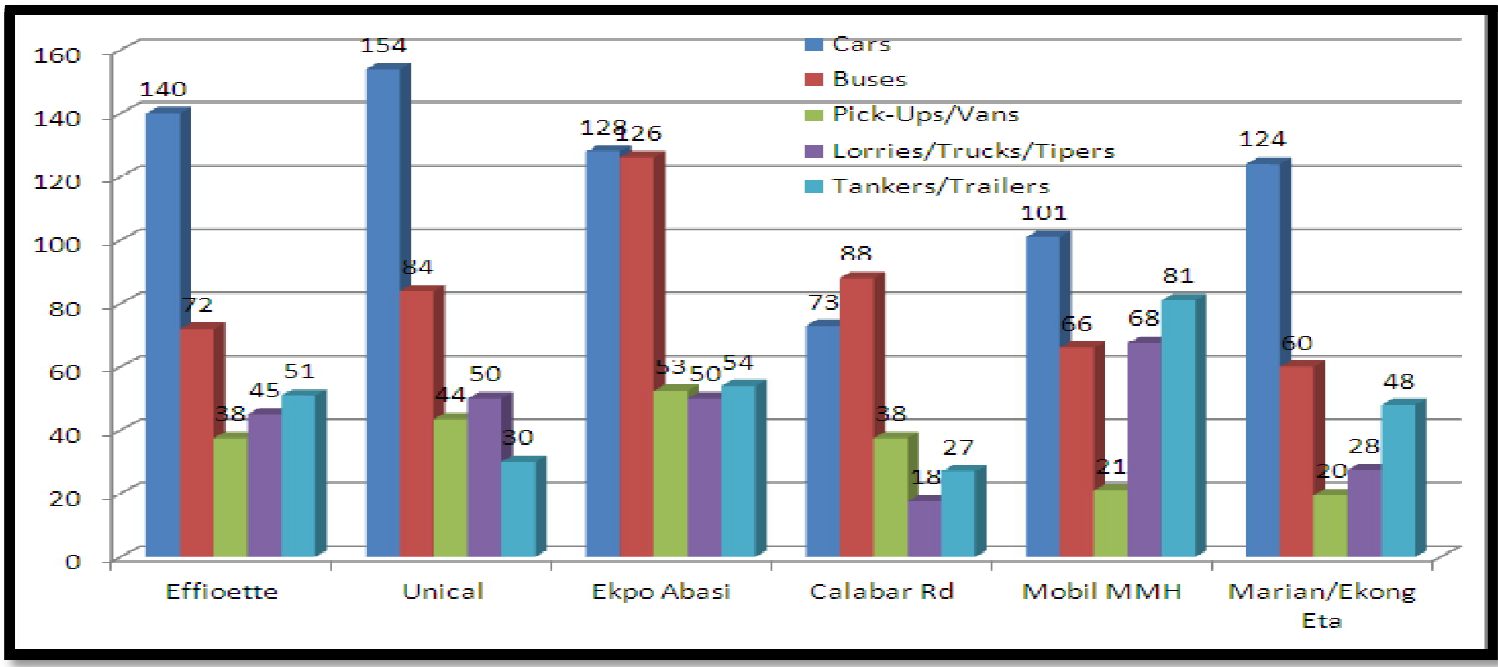

Figure 3: Traffic Violations of Different Modes in Sampled Intersections

\subsection{Logistic Regression Analysis of Driver Behaviour in Calabar}

A logistic regression analysis was conducted to predict the behaviour of 347 drivers in Calabar using reasons for violating traffic, gender, age, education ownership of valid driver license and driver category as predictors. The model includes dummy variables for each reason for traffic violation contrasted against the indiscipline-related causes, male contrasted against gender, 35-45 years of age contrasted against age distribution of sampled drivers, higher national diploma (HND)/ BSc education contrasted against general education of drivers and yes ownership contrasted against owner ship status of driver license. The results are presented in Model 1 of Table 9.

A test of the full model against a constant only model was statistically significant, indicating that the predictors as a set reliably distinguished between traffic violators and non-traffic violators (chi square $=89.113, \mathrm{p}<.001$ with $\mathrm{df}=8$ ). 
Nagelkerke's $\mathrm{R}^{2}$ of .815 indicated a moderately strong relationship between prediction and grouping. Prediction success overall was $94.2 \%$ (91.3\% for non-violation and 96.2\% for traffic violation. The Wald criterion demonstrated that impatience, emergency, weak law, and other factors made a significant contribution to prediction in model $1(p=.000)$, while only ignorance did not $(\mathrm{p}=.999)$.

$\operatorname{Exp}(\mathrm{B})$ value indicates that when impatience is raised by one unit (one person) the odds ratio is 100 times as large and therefore householders (drivers) are 100 more times likely to violate traffic. Furthermore, Exp(B) value indicates that when emergency is raised by one unit (one person) the odds ratio is 812 times as large and therefore householders (drivers) are 812 more times likely to violate traffic under emergency conditions. $\operatorname{Exp}(\mathrm{B})$ value indicates that when weak law is raised by one unit (one person) the odds ratio is 177 times as large and therefore householders (drivers) are 212 more times likely to violate traffic given weak law enforcement. $\operatorname{Exp}(B)$ value indicates that when other factors (perhaps unidentified or a combination of factors) is raised by one unit (one person) the odds ratio is 16 times as large and therefore householders (drivers) are 16 more times likely to violate traffic (Table 9). Other independent variables used as covariates in the model include sex, age, education, possession of a valid driver license and class of driving. None of them proved to strongly predict traffic violation as there are all statistically not significant $p>.000$ (Table 9 ).

\begin{tabular}{|c|c|c|c|c|c|}
\hline \multicolumn{6}{|c|}{ 95\% CI for Odds Ratio } \\
\hline & B (SE) & Lower & Odds ratio & Upper & Sig. \\
\hline Included & & & & & \\
\hline Constant & $15.317(1.077)$ & & & & \\
\hline Reasons for violation & & & & & \\
\hline Impatience & $4.608(.666)$ & 27.188 & 100.330 & 370.233 & .000 \\
\hline Emergency & $6.700(.769)$ & 180.137 & 812.687 & $3.666 \mathrm{E} 3$ & .000 \\
\hline Ignorance & 25.405 (1.607) & .000 & 1.079 & & .999 \\
\hline Weak law & $5.361(1.160)$ & 21.912 & 212.910 & 2.069E3 & .000 \\
\hline Other & $2.797(.816)$ & 3.315 & 16.397 & 81.103 & .001 \\
\hline Sex & & & & & \\
\hline $\operatorname{Sex}(1)$ & $-.095(.547)$ & .311 & .909 & 2.657 & .862 \\
\hline Age & & & & & .286 \\
\hline $\operatorname{Age}(1)$ & .875 (1.397) & 155 & 2.399 & 37.063 & .531 \\
\hline $\operatorname{Age}(2)$ & $-.867(1.270)$ & .035 & .420 & 5.066 & .495 \\
\hline Age(3) & $.168(1.252)$ & .102 & 1.183 & 13.764 & .893 \\
\hline Age(4) & $-.331(1.395)$ & .047 & .718 & 11.058 & .813 \\
\hline Education & & & & & .500 \\
\hline Education(1) & $.643(1.650)$ & .075 & 1.902 & 48.239 & 697 \\
\hline Education(2) & $-1.072(1.722)$ & .012 & .342 & 10.016 & .534 \\
\hline Education(3) & $-.140(1.440)$ & .052 & .870 & 14.616 & .923 \\
\hline Education(4) & $-.165(1.322)$ & .064 & .848 & 11.310 & .901 \\
\hline Education(5) & $-1.247(1.225)$ & .026 & .287 & 3.171 & .309 \\
\hline Education(6) & $-1.446(1.270)$ & .020 & .236 & 2.836 & .255 \\
\hline Ownership of license & & & & & .024 \\
\hline Driver license(1) & $1.368(.606)$ & 1.198 & 3.926 & 12.865 & .779 \\
\hline Driving class & & & & & 999 \\
\hline Driver category(1) & $-18.112(1.077)$ & .000 & .000 & . & .999 \\
\hline Driver category(2) & $-19.202(1.077)$ & .000 & .000 & . & .999 \\
\hline Driver category(3) & $-18.077(1.077)$ & .000 & .000 & & .999 \\
\hline
\end{tabular}

Table 9: Logistic (Binary) Regression Analysis of Nagelkerke Pseudo R-Square 8.2\% Chi-Square 89.1, $\mathrm{Df}=8, \mathrm{P} \varangle 0.01$

a. Variable(S) Entered On Step 1: Sex, Age, Education, Driver License, and Driver Category. Note: R2 =.06 (Hosmer \& Lemeshow), .60 (Cox \& Snell), .11 (Nagelkerke). Model X2 (1) =19.56, P<.01.*P<.01

\section{Conclusion and Policy Recommendations}

Traffic violation is one of the problems of urbanization facing most cities in Nigeria. The study examined traffic violation problems at intersections and driver behaviour of a cross section of urban residents in Calabar, the study in line with reviewed literature has shown that when traditional cities begin to experience increase urban population growth and level of commercial activities, there is bound to be mobility conflicts if not properly managed. It is eminent that strict law enforcement be put in place to check drivers' behaviour. It is also necessary for research to be done by relevant stakeholders in details in order to curb this behaviour of drivers and other aspects of urban mobility in the city to push the research frontier further and come up with practical solutions in managing the situation.

The following recommendations not limited to these, are suggested: 
- Enforcement of Traffic Laws: Well designed and well operated law enforcement programs can have significant effect on highway safety. It is well established, for instance, that an effective way to reduce the occurrence of crashes and their severity is to have jurisdiction-wide programs that enforce an effective law against driving under the influence of alcohol (DUI) or driving without seat belts. When that law is vigorously enforced with well- trained officers, the frequency and severity of highway crashes can be significantly reduced. This should be an important element in any comprehensive highway safety program.

- Strategies directed at improving the safety management system: There should be a sound organizational structure in place, as well as an infrastructure of laws, policies, etc. to monitor, control, direct and administer a comprehensive approach to highway safety. It is important that a comprehensive program not to be limited to one jurisdiction, such as the state DoT.

- Road safety awareness campaign: This can be coordinated by the Department of Public Transport (DoPT) and Federal Road Safety Corps (FRSC) by flagging campaigns to educate motorists on the dangers of violating the traffic rule. This also can be done through jingles on the television and radio, sharing of the campaign flyers, using social media and road walk to help create awareness. These can also be used to reduce road casualty levels

\section{References}

i. Aberg, L., \& Rimmo, P. A. (1998). Dimensions of aberrant driver behaviour. Ergonomics, 41(1), 39-56.

ii. Alm, H., \& Nilsson, L. (1995). The effects of a mobile telephone task on driver behaviour in a car following situation. Accident Analysis \& Prevention, 27(5), 707-715.

iii. Aderamo, A.J. (2012. Urban Transport Problems: and Challenges in Nigeria: a planner view. In prime Research Journal. Vol. 2 pp 198203.

iv. Dia, H. (2002). An agent-based approach to modelling driver route choice behaviour under the influence of real-time information. Transportation Research Part C: Emerging Technologies, 10(5-6), 331-349.

v. Fuller, R. (2005). Towards a general theory of driver behaviour. Accident Analysis \& Prevention, 37(3), 461-472.

vi. Gardner, M. J., \& Altman, D. G. (1986). Confidence intervals rather than P values: Estimation rather than hypothesis testing. British Medical Journal, 292, 746-750.

vii. Lajunen, T., \& Summala, H. (2003). Can we trust self-reports of driving? Effects of impression management on driver behaviour questionnaire responses. Transportation Research Part F: Traffic Psychology and Behaviour, 6(2), 97-107.

viii. Lajunen, T., Parker, D., \& Summala, H. (2004). The Manchester driver behaviour questionnaire: a cross-cultural study. Accident Analysis \& Prevention, 36(2), 231-238.

ix. Lourens, P. F., Vissers, J. A. M. M., \& Jessurun, M. (1999). Annual mileage, driving violations, and accident involvement in relation to drivers' sex, age, and level of education. Accident Analysis and Prevention, 31, 593-597.

x. Massie, D. L., Campbell, K. L., \& Williams, A. F. (1995). Traffic accident involvement rates by driver age and gender. Accident Analysis and Prevention, 27, 73-87

xi. Rodriguez, D. (2009). Active transportation: making the link from transportation to physical activity and obesity. San Diego: Active Living Research.

xii. Sule, R.O. (2008). Sustainable Urban Physical Development in Nigeria: a shift in Paradigm, Thumbprints International Company, Calabar.

xiii. Summala, H. (1996). Accident risk and driver behaviour. Safety Science, 22(1-3), 103-117.

xiv. Schmidt, F. L. (1992). What do data really mean? Research findings, meta-analysis, and cumulative knowledge in psychology. American Psychologist, 47, 1173-1181.

xv. West, R., French, D., Kemp, R., \& Elander, J. (1993). Direct observation of driving, self-reports of driver behaviour, and accident involvemen 